\title{
Produção de brotações e enraizamento de miniestacas de Piptocarpha angustifolia
}

\author{
Aurea Portes Ferriani ${ }^{1}$, Katia Christina Zuffellato-Ribas ${ }^{2}$, Cristiane Vieira Helm³ ${ }^{3}$ Adriana Boza², Ivar Wendling ${ }^{3}$, \\ Henrique Soares Koehler ${ }^{2}$ \\ ${ }^{1}$ Universidade Tuiti do Paraná, Rua Dydnei Rangle Santos, 238, Santo Inácio, CEP, 82010-330, Curitiba, PR, Brasil \\ ${ }^{2}$ Universidade Federal do Paraná (UFPR), Centro Politécnico, Jardim das Américas, CP 19031, CEP 81531-980, Curitiba, PR, Brasil \\ ${ }^{3}$ Embrapa Florestas, Estrada da Ribeira, Km 111, CP 319, CEP 83411-000, Colombo, PR, Brasil
}

"Autor correspondente:

apferriani@ig.com.br

Termos para indexação:

Vassourão-branco

Miniestaquia

Juvenilidade

Index terms:

Vassourão-branco

Minicutting

Juvenility

Histórico do artigo:

Recebido em 27 out 2010

Aprovado em 10 mai 2011

Publicado em 30 set 2011

doi: 10.4336/2011.pfb.31.67.257
Resumo - Piptocarpha angustifolia Dusén ex. Malme é uma espécie arbórea nativa brasileira, pioneira, pertencente à Floresta Ombrófila Mista, com potencialidades para recuperação de ecossistemas degradados e implantação em sistemas agrossilvipastoris. Sua propagação pela via seminal apresenta produção irregular e número reduzido de sementes viáveis além de experimentos de estaquia com ramos semilenhosos não apresentarem resposta para enraizamento adventício. Este trabalho buscou avaliar o potencial de enraizamento da espécie pela técnica da miniestaquia com uso de minicepas originadas por sementes e cultivadas sob sistema semi-hidropônico. As brotações coletadas foram imersas em solução de ácido ascórbico a 1\% e as miniestacas confeccionadas com $5 \mathrm{~cm}$ de comprimento e manutenção do par de folhas no ápice, instaladas em substrato contendo vermiculita média e casca de arroz carbonizada (1:1 $\mathrm{V} \mathrm{v}^{-1}$ ). Decorridos 90 dias, verificou-se maior produção de miniestacas no inverno e primavera, variando entre 113,4 e 259,2 miniestacas por metro quadrado ao mês. O enraizamento adventício chegou a $45 \%$ no inverno com número de raízes igual a 6,3 e comprimento médio de $9,8 \mathrm{~cm}$, sem utilização de fitorregulador.

\section{Sprouts production and rooting of Piptocarpha angustifolia minicuttings}

\begin{abstract}
Piptocarpha angustifolia Dusén ex. Malme (Asteraceae) is a brazilian native and pioneer tree species, occuring in Araucária Forest, with potential to ecosystem restorarion and introduction in forest, agriculture and pasture systems. Its propagation by seed presents irregular production and low number of feasible seeds while vegetative propagation by cutting of mature plants with semihardwood shoots didn't present rooting response. This work aimed to evalue adventitious rooting by minicutting technique using minisprouts from seeds. The minisprouts were collected and dipped in ascorbic acid solution (1\%) and minicuttings were produced with $5 \mathrm{~cm}$ lenght mantaining a pair of leaves in the apex installed in a medium with vermiculite and carbonized rice husk $\left(1: 1 \mathrm{v} \mathrm{v}^{-1}\right)$. The evaluation was made after 90 days considering percentage of rooting minicuttings, number and lenght average for minicuttings, percentage of living minicuttings, percentage of minicuttings with callus and dead minicuttings. The higher production of minicuttings was verified in winter and spring, varying between 113.4 to 259.2 units for square meter a month. The adventitious rooting reached $45 \%$ in winter with 6.3 roots and an average of $9.8 \mathrm{~cm}$ of length, without using plant growth regulator.
\end{abstract}




\section{Introdução}

A miniestaquia é uma técnica de propagação vegetativa derivada da estaquia convencional. Consiste na utilização de brotações de plantas propagadas pelo processo de estaquia, ou mudas produzidas por semente (Alfenas et al., 2004), dispensando o rejuvenescimento in vitro (Wendling et al., 2000). É uma alternativa que visa suprir a necessidade do resgate da juvenilidade do material vegetativo, apontada por diversos autores como fator limitante da capacidade de indução radicial gerada pelo processo de maturação (Bonga, 1982; Zobel; Talbert, 1984; Hartmann, 2002).

$\mathrm{O}$ interesse na introdução da miniestaquia para diversas espécies está relacionado à redução da área produtiva (adoção do minijardim), diminuição do período de enraizamento e aclimatação, além da redução de reguladores vegetais para indução do enraizamento (Higashi et al., 2000; Xavier et al., 2003b; Wendling et al., 2005).

O desenvolvimento da técnica teve início na década de 1990 para o gênero Eucalyptus (Higashi et al., 2000), devido às limitações impostas pelo cultivo in vitro (Wendling, 2002; Almeida et al., 2007). Sua aplicação tem possibilitado a propagação de genótipos de difícil enraizamento, com ampliação da porcentagem de miniestacas enraizadas e melhoria do sistema radicial, influenciando diretamente o desempenho de mudas em campo (Alfenas et al., 2004). Estes aspectos são apontados por Xavier \& Santos (2002) como contribuição significativa para ampliação da base silvicultural de espécies nativas com fins econômicos, recuperação de áreas (RAD) e ecossistemas degradados (RED) (Carpanezzi, 2005), possibilitando também o resgate de genótipos adultos de interesse. Além disso, pode representar uma alternativa potencialmente viável para espécies lenhosas cujo processo de estaquia convencional resulta em percentual de enraizamento variável e baixa qualidade na formação de raízes (Souza $\&$ Almado, 2002). Esta técnica também pode ser adaptada à realidade de pequenos e médios proprietários rurais para produção de mudas destinadas a plantios dirigidos ou para utilização em processos de recuperação, gerando incremento de renda.

Para a espécie Piptocarpha angustifolia Dusén, a adoção da miniestaquia pode representar uma alternativa para propagação e produção significativas de mudas, uma vez que estudos realizados anteriormente demonstraram dificuldade de germinação pela baixa viabilidade das sementes, além do não enraizamento manifestado por estacas semilenhosas provenientes de material adulto coletado nas quatro épocas do ano e submetidas a diferentes tratamentos contendo ácido indol butírico (Ferriani et al., 2005; Ferriani, 2006). Nesse sentido, o presente trabalho buscou verificar a produtividade de brotações (miniestacas) ao longo das quatro estações do ano e o seu enraizamento para as diferentes épocas de coleta.

\section{Material e métodos}

Sementes de plantas-matrizes adultas foram coletadas no Município de Curitiba, Paraná, no mês de dezembro de 2006 e colocadas para germinar em substrato formado por vermiculita média e casca de arroz carbonizada $\left(1: 1 \mathrm{v} \mathrm{v}^{-1}\right)$. Após 90 dias, as plântulas repicadas foram transplantadas para tubetes $\left(55 \mathrm{~cm}^{3}\right)$ contendo o mesmo substrato e mantidas em casa-de-vegetação sob sistema de nebulização intermitente $\left(25^{\circ} \mathrm{C} \pm 2\right.$, e umidade superior a $\left.80 \%\right)$.

Em agosto de 2007, quando as mudas tinham 8 meses de idade e altura média de $30 \mathrm{~cm}$, foram transferidas para a estufa, sob sistema semi-hidropônico (canaletão) composto por areia média lavada, e sofreram poda dos ápices para estímulo à produção de brotações. As minicepas receberam solução nutritiva previamente formulada, utilizada por Brondani (2008) para Eucalyptus benthamii $\mathrm{x}$ dunnii, por gotejamento três vezes ao dia a uma vazão total diária de $5 \mathrm{Lm}^{-2}$. A solução nutritiva foi composta por monoamônio fosfato $\left(0,04 \mathrm{gL}^{-1}\right)$, sulfato de magnésio $\left(0,40 \mathrm{gL}^{-1}\right)$, nitrato de potássio $\left(0,44 \mathrm{gL}^{-1}\right)$ sulfato de amônio $\left(0,31 \mathrm{gL}^{-1}\right)$, cloreto de cálcio $(0,79$ $\left.\mathrm{gL}^{-1}\right)$, ácido bórico $\left(2,88 \mathrm{mgL}^{-1}\right)$, sulfato de manganês $\left(3,70 \mathrm{mgL}^{-1}\right)$, molibdato de sódio $\left(0,18 \mathrm{mgL}^{-1}\right)$, sulfato de zinco $\left(0,74 \mathrm{mgL}^{-1}\right)$ e hidroferro em pó $\left(81,80 \mathrm{mgL}^{-1}\right)$. Outra parte das minicepas mantidas em porta-mudas receberam fertirrigação semanal, composta de sulfato de amônio $\left(4 \mathrm{gL}^{-1}\right)$ ou uréia $\left(2 \mathrm{gL}^{-1}\right)$, superfosfato simples $\left(1 \mathrm{gL}^{-1}\right)$, cloreto de potássio $\left(4 \mathrm{gL}^{-1}\right)$ e fertilizante FTE BR $10\left(1 \mathrm{gL}^{-1}\right)$.

As coletas de brotações tiveram início em outubro de 2007, quando foram iniciados os experimentos de miniestaquia. Como medida preventiva à oxidação, as bases das brotações foram imersas em soluções a $1 \%$ de ácido ascórbico. 
Cada miniestaca foi confeccionada utilizando-se as brotações obtidas das minicepas, desprezando-se a porção apical e mantendo-se o comprimento aproximado de $5 \mathrm{~cm}$ e diâmetro de $0,5 \mathrm{~cm}$. Foram preparados com corte em bisel na base e reto na porção superior, mantendo-se duas folhas com área reduzida à metade, com objetivo de reduzir a perda de água pela transpiração foliar. Durante o processo de confecção, as estacas foram mantidas em baldes com água para evitar desidratação e em seguida lavadas em água corrente. Posteriormente, foram instaladas em tubetes de $55 \mathrm{~cm}^{3}$ contendo o mesmo substrato utilizado para as minicepas.

Após 90 dias da instalação foram analisadas as seguintes variáveis: porcentagem de miniestacas enraizadas, porcentagem de miniestacas com calos (sem raízes e com calos), porcentagem de miniestacas vivas (sem raízes e sem calos) e porcentagem de miniestacas mortas, número médio de raízes por miniestaca e comprimento médio das três maiores raízes por miniestaca.

O delineamento experimental utilizado foi inteiramente casualizado, composto por quatro tratamentos (períodos de coleta de miniestacas) correspondentes a primavera (22 de setembro a 21 de dezembro), verão (22 de dezembro a 21 de março), outono (22 de março a 21 de junho) e inverno (22 de junho a 21 de setembro), formado por quatro repetições de 20 miniestacas por parcela, totalizando 80 miniestacas em cada estação. A homogeneidade das variâncias dos tratamentos foi testada pelo teste de Bartlett e as médias dos tratamentos foram comparadas pelo teste de Tukey, ao nível de 5\% de probabilidade. Para a realização da análise estatística foi utilizado o programa MSTAT-C, versão 2.10 (Russel D. Freed, MSTAT Director, Crop and Soil Science Department, Michigan State University, EUA).

\section{Resultados e discussão}

\section{Sobrevivência de minicepas e produção de brotações}

$\mathrm{Na}$ Tabela 1 são apresentados os resultados da produção de brotações (miniestacas) provenientes de minicepas de $P$. angustifolia ao longo de 13 coletas sucessivas durante o período de outubro de 2007 a dezembro de 2008. De acordo com as avaliações, a época de coleta correspondente à primavera de 2008 foi o período de maior média de produtividade de brotações, seguida das épocas do inverno e outono. Estes resultados concordaram parcialmente com os obtidos por Brondani (2008), que verificou a superioridade da produção de brotações em clones de Eucalyptus benthamii Maiden \& Cambage x Eucalyptus dunnii Maiden nas estações da primavera e verão.

Considerando-se as médias gerais de brotações por minicepa, a primavera constituiu o período de maior produtividade em duas épocas ( $\mathrm{N}=5,1 \mathrm{e} \mathrm{N}=6,7)$, seguida do inverno $(\mathrm{N}=4,9)$, outono $(\mathrm{N}=4,8)$ e verão $(\mathrm{N}=4,4)$. Porém, quando foram comparadas as produtividades das minicepas dentro de cada época, a produtividade estimada para a primavera alcançou 259,2 brotações por minicepa por metro quadrado, seguida pelo outono $(218,7)$ e verão $(202,5)$.

$\mathrm{O}$ verão apresentou o menor valor de produção de brotações em função da redução do número de minicepas durante o período de adaptação ao sistema semihidropônico. A elevação da temperatura registrada nessa época merece ser destacada, uma vez que o material permaneceu instalado em ambiente sem controle de temperatura, o que pode ter ocasionado estresse térmico e sensibilização das minicepas. Torres (2003) observou que os teores de carboidratos em dois clones de eucalipto (E. saligna e E. grandis) na época do verão apresentaram aumento geral de brotações e redução do intervalo entre coletas, atribuídas à elevação da temperatura e ao uso intensivo de fertirrigação.

De maneira geral, foi verificada a variação da produtividade de miniestacas por minicepa em relação ao período de coleta, onde períodos de temperatura mais elevada contribuíram para o desenvolvimento geral de gemas e crescimento acentuado de brotações jovens. $\mathrm{O}$ aumento de produtividade foi verificado nos períodos correspondentes às estações do ano com temperaturas elevadas ou em períodos atípicos onde ocorreu elevação dessa variável (Tabela 1), corroborando com dados obtidos por Brondani (2008) para E. benthamii x dunnii.

$\mathrm{O}$ estímulo à formação de brotações proporcionado pela elevação da temperatura associado à coleta seletiva de brotações ocasionou a redução do intervalo entre coletas (coletas 4 a 7) a 20 dias (Tabela 1), o que confirma a viabilidade do sistema a partir do estabelecimento das minicepas. Outros trabalhos avaliados apresentaram intervalos médios de 30 dias (Wendling; Xavier, 2003; Cunha et al., 2005; Wendling et al., 2007). 
Tabela 1. Número de minicepas, intervalo entre coletas de brotações (miniestacas) produzidas em cada estação e médias de produtividade, em cada estação, no período de 2007 a 2008.

\begin{tabular}{|c|c|c|c|c|c|c|}
\hline Coleta & Data & $\begin{array}{c}\text { Intervalo } \\
\text { entre } \\
\text { coletas }\end{array}$ & $\begin{array}{c}\mathrm{N}^{\circ} \\
\text { minicepas }\end{array}$ & $\begin{array}{l}\text { Brotações/ coleta } \\
\text { (miniestacas) }\end{array}$ & $\begin{array}{c}\text { Média } \\
\text { brotações/ minicepa }\end{array}$ & $\begin{array}{c}\text { Brotações } \\
\text { m }^{2} \text { mês }^{-1}\end{array}$ \\
\hline & & & Primavera & & & \\
\hline 1 & $19 / 10 / 07$ & & 40 & 79 & 2 & 160,3 \\
\hline 2 & 19/11/07 & 31 & 38 & 76 & 2 & 162,0 \\
\hline 3 & $14 / 12 / 07$ & 25 & 21 & 23 & $1,1 *$ & 89,1 \\
\hline Média & & 28 & 33 & & & \\
\hline \multirow[t]{2}{*}{ Total } & & & & 178 & 5,1 & 411,4 \\
\hline & & & Verão & & & \\
\hline 4 & $01 / 02 / 08$ & 18 & 16 & 31 & 1,9 & 157,1 \\
\hline 5 & $29 / 02 / 08$ & 28 & 15 & 37 & 2,5 & 202,5 \\
\hline Média & & 23 & 15 & & & \\
\hline \multirow[t]{2}{*}{ Total } & & & & 68 & 4,4 & 359,6 \\
\hline & & & Outono & & & \\
\hline 6 & $04 / 04 / 08$ & 36 & 12 & 25 & 2,1 & 170,1 \\
\hline 7 & $11 / 04 / 08$ & 7 & 11 & 30 & 2,7 & 218,7 \\
\hline Média & & 21 & 11 & & & \\
\hline \multirow[t]{2}{*}{ Total } & & & & 55 & 4,8 & 388,8 \\
\hline & & & Inverno & & & \\
\hline 8 & $27 / 06 / 08$ & $46 * *$ & 28 & 45 & 1,4 & 113,4 \\
\hline 9 & $22 / 08 / 08$ & 56 & 24 & 48 & 2,0 & 162,0 \\
\hline 10 & $19 / 09 / 08$ & 28 & 26 & 39 & 1,5 & 121,5 \\
\hline Média & & 43 & 26 & & & \\
\hline \multirow[t]{2}{*}{ Total } & & & & 132 & 4,9 & 396,9 \\
\hline & & & Primavera & & & \\
\hline 11 & $24 / 10 / 08$ & 35 & 24 & 36 & 1,5 & 121,5 \\
\hline 12 & $14 / 11 / 08$ & 21 & 25 & 53 & 2,0 & 162,0 \\
\hline 13 & $19 / 12 / 08$ & 36 & 24 & 76 & 3,2 & 259,2 \\
\hline Média & & 31 & 24 & & & \\
\hline Total & & & & 165 & 6,7 & 542,7 \\
\hline
\end{tabular}

* Morte de brotações ** Intervalo para reposição de minicepas e reinício das coletas

Houve redução do número de minicepas ao longo do período avaliado (coletas 1 a 7), atribuída ao período de aclimatação do material ao leito de enraizamento durante a implantação do minijardim clonal. Foi observado que as minicepas instaladas em canaletão apresentavam oxidação logo após a coleta de brotações. Tal fato pode ser relacionado à redução da área foliar proveniente das podas para remoção de brotações e pode ter contribuído para o estresse das minicepas, ocasionando a morte precoce destas, mesmo com a manutenção parcial das brotações formadas. Embora não tenham sido verificadas citações sobre o limite de remoção de brotações em cada coleta, Cunha et al. (2005) recomendam que os estresses provenientes das podas consecutivas de minicepas sejam minimizados.

A utilização de solução previamente formulada para fertirrigação de Eucalyptus pode ter contribuído para a mortalidade das minicepas. As concentrações elevadas de nutrientes possivelmente causaram fitotoxicidade no material, ocasionando a redução inicial de minicepas. Dessa maneira, foi utilizada uma rega diária complementar, com a finalidade de diluir o excesso de nutrientes, o que se mostrou uma prática eficiente. Segundo Titon et al. (2003), a utilização de aspersão 
semanal contendo somente água é recomendada com a finalidade de remover o acúmulo de sais no substrato.

Comparando-se os valores de produtividade obtidos neste trabalho, houve variação entre 1,1 e 3,2 brotações por minicepa (Tabela 1), situando-se entre os valores obtidos para espécies nativas brasileiras, respectivamente na miniestaquia de cedro (Cedrella fissillis) por Xavier et al. (2003b), em corticeira-do-mato (E. falcata) por Cunha et al. (2003) e em jequitibá rosa (Cariniana legalis (Mart.) Kuntze) por Santos (2002). Entretanto, encontram-se abaixo dos valores obtidos em eucalipto, que variaram entre 1,9 e 9,7 miniestacas por minicepa (Wendling et al., 2000; Titon et al., 2003; Wendling et al., 2003; Cunha et al., 2005).

Em avaliações da técnica para outras espécies, Santos (2002) utilizou sistemas de jardim miniclonal em tubetes de $200 \mathrm{~cm}^{3}$, com coletas a cada 30 dias, obtendo as seguintes produções de miniestacas por minicepa: 1,3 para cedro rosa; 1,1 para mogno; 1,6 para angico vermelho e 3,8 para jequitibá rosa. Levando-se em consideração o intenso processo de melhoramento a que já foi submetido o gênero Eucalyptus, pode-se inferir que a partir da adequação de manejo da espécie em estudo, principalmente em termos de nutrição, será possível aumentar o número de brotações por minicepa.

Com relação à sobrevivência das minicepas pode-se verificar que apesar da redução inicial das minicepas (coletas 1 a 7), atribuídas à adaptação inicial ao sistema, seguida dos possíveis sintomas posteriores de fitoxicidade, a partir da coleta de número 8 constatouse regularidade desse número (Tabela 1), sugerindo a adaptação do material vegetal às condições de nutrição fornecidas, o que pode ser verificado pelo número reduzido de minicepas perdidas entre as coletas 8 e 13 . Essas variações do número de minicepas também foram verificadas por Wendling et al. (2007) para miniestaquia de erva-mate (Ilex paraguariensis St. Hill.), onde foram realizadas onze coletas consecutivas com diminuição inicial e posterior acréscimo na produção de brotações. Estes resultados indicam a viabilidade do sistema para obtenção de propágulos e posterior desenvolvimento de outras pesquisas em propagação (Wendling, 2002; Wendling et al., 2003; Ferriani, 2006).

Embora a utilização de fertirrigação (aérea ou por subsuperfície) contendo solução de macro e micronutrientes seja apontada como favorável para a maior produtividade de brotações (Alfenas et al., 2004; Paiva; Gomes, 1993), para manutenção do turgor hídrico e do status nutricional das minicepas (Xavier et al., 2003a), no caso da espécie P. angustifolia, essa prática pode ter sido responsável pelos sintomas de fitotoxicidade apresentados, em vista de não ter sido desenvolvida uma solução específica para a espécie. A sensibilidade das minicepas ao excesso de nutrição também pode estar relacionada ao hábito pioneiro dessa espécie em se estabelecer naturalmente em solos degradados e nutricionalmente deficientes (Seitz, 1976).

Apesar da redução inicial do número de minicepas, o número de brotações apresentou elevação durante a condução dos experimentos, o que gerou volume suficiente de miniestacas para a execução dos experimentos de enraizamento.

\section{Enraizamento de miniestacas}

Os períodos de instalação de experimentos de miniestaquia avaliados foram outubro de 2007 (primavera), janeiro (verão), abril (outono) e junho de 2008 (inverno). De acordo com a análise de variância, não houve efeito significativo das épocas de coleta para a variável porcentagem de miniestacas enraizadas, porém houve diferença significativa entre os tratamentos para as variáveis número médio de raízes e comprimento médio das três maiores raízes.

A comparação de médias (Tabela 2) dos tratamentos realizados nas épocas de coleta (primavera de 2007, outono e inverno de 2008) demonstrou que as porcentagens de enraizamento apresentaram valores médios semelhantes para miniestacas coletadas nas épocas da primavera e inverno e superiores ao período de coleta do outono.

Tabela 2. Porcentagens de miniestacas de P. angustifolia enraizadas, número médio de raízes por miniestaca e comprimento médio das três maiores raízes por miniestaca, coletadas na primavera de 2007, outono e inverno de 2008, Curitiba, PR, 2008.

\begin{tabular}{cccc}
\hline $\begin{array}{c}\text { Épocas } \\
\text { de coleta }\end{array}$ & $\begin{array}{c}\text { Miniestacas } \\
\text { enraizadas } \\
(\%)\end{array}$ & $\begin{array}{c}\text { Número } \\
\text { médio } \\
\text { de raízes }\end{array}$ & $\begin{array}{c}\text { Comprimento } \\
\text { médio de } \\
\text { raízes } \\
\text { (cm) }\end{array}$ \\
\hline $\begin{array}{c}\text { Primavera } \\
\text { (outubro de 2007) }\end{array}$ & $45,0 \mathrm{~A}$ & $2,7 \mathrm{~B}$ & $2,7 \mathrm{~B}$ \\
$\begin{array}{c}\text { Outono } \\
\text { (abril de 2008) }\end{array}$ & $17,5 \mathrm{~A}$ & $1,1 \mathrm{C}$ & $3,4 \mathrm{~B}$ \\
$\begin{array}{c}\text { Inverno } \\
\text { (junho de 2008) }\end{array}$ & $45,0 \mathrm{~A}$ & $6,3 \mathrm{~A}$ & $9,8 \mathrm{~A}$ \\
\hline
\end{tabular}

Médias seguidas da mesma letra nas colunas não diferem estatisticamente pelo teste de Tukey ao nível de $5 \%$ de probabilidade. 
Houve mortalidade geral dos propágulos na avaliação realizada para miniestacas coletadas no verão, que apresentaram perda de folhas e oxidação generalizada. Mesmo sob regime de temperatura e umidade controladas, as miniestacas de $P$. angustifolia demonstraram suscetibilidade à elevação de temperatura, fato também verificado em estacas semilenhosas desta espécie coletadas na mesma época (Ferriani, 2006).

Embora na primavera e inverno tenham sido obtidas as mesmas porcentagens para a variável miniestacas enraizadas de $P$. angustifolia, as variáveis número e comprimento médio de raízes por miniestaca foram numericamente superiores no inverno. De acordo com esses resultados, pode-se sugerir que as mudas produzidas a partir de miniestacas coletadas nesta época podem apresentar um desempenho mais satisfatório em campo devido ao sistema radicial mais desenvolvido, o que contribui para a absorção mais eficiente de nutrientes e consequente crescimento da muda (Reis et al., 2000).

Os resultados de enraizamento adventício aproximaram-se àqueles obtidos por Brondani (2008), que obteve as maiores porcentagens de enraizamento em miniestacas coletadas no inverno, seguida do outono para espécies de eucalipto provenientes de regiões subtropicais. Também corresponderam ao comportamento avaliado em minicepas de Pinus taeda L. instaladas em casa-de-vegetação e que apresentaram os maiores percentuais de enraizamento sob ambiente controlado na primavera e verão (Alcantara, 2005), assim como na espécie corticeira-do-mato (Erythrina falcata Bentham) (Wendling et al., 2005). No caso de $P$. angustifólia, pode-se inferir que as reservas acumuladas ao longo do outono possam ter contribuído para o enraizamento avaliado no inverno e na época seguinte (primavera). A partir desse período, com a ocorrência da elevação de temperatura e início da fase reprodutiva, as reservas possivelmente poderiam ser disponibilizadas para a formação de inflorescências e frutos, dificultando a iniciação radicial para essa espécie (Ferriani, 2006).

$O$ período de permanência das miniestacas de $P$. angustifolia em casa-de-vegetação foi ampliado para 90 dias, uma vez que experimentos preliminares com períodos menores exibiram elevado número de miniestacas com formação de calos. Esse período difere consideravelmente para outras espécies, que foram mantidas no leito de enraizamento por um período médio de 30 dias, conforme verificado em corticeira-do-mato (E. falcata) por Wendling et al. (2005), em eucalipto (E. grandis) (Wendling; Xavier, 2003) e para cedro (C. fissilis) (Xavier et al., 2003a).

Foi observado que a imersão da base das miniestacas em solução aquosa contendo $1 \%$ de ácido ascórbico pode ter contribuído para a sobrevivência das miniestacas, favorecendo o processo de enraizamento adventício. Esta prática foi utilizada com a finalidade de inibir o processo de oxidação das bases dos propágulos, a qual gera o escurecimento dos tecidos e consequente morte, impedindo o processo de iniciação radicial. Embora este procedimento não tenha sido citado em pesquisas envolvendo estaquia ou miniestaquia, a utilização de compostos antioxidantes, como polivinilpirrolidona (PVP), ácido cítrico (Ferrari et al., 2004) e ácido ascórbico têm sido amplamente verificada em meios de cultura para inibição da oxidação em cultura de tecidos. Além disso, a aplicação desses compostos foi citada como significativa na enxertia de culturas como ervamate (Ilex paraguariensis) (Ferrari et al., 2004). Dessa maneira esta prática preventiva pode ser difundida para metodologias que impliquem em injúria de tecidos que possam apresentar esta característica.

\section{Miniestacas com calos, vivas e mortas}

De acordo com a análise de variância houve efeito significativo dos tratamentos para as variáveis porcentagem de miniestacas com calos, porcentagem de miniestacas vivas e porcentagem de miniestacas mortas.

Em função dos valores médios da variável porcentagem de miniestacas com calos (Tabela 3), o outono apresentou o maior valor numérico, seguido da primavera e inverno, respectivamente. Devido aos elevados índices observados para as variáveis porcentagem de miniestacas com calos e vivas, após a avaliação, as miniestacas foram mantidas em casa-de-vegetação na tentativa de promover o enraizamento posterior, fato não confirmado devido à morte desses propágulos sem formação de raízes. 
Tabela 3. Porcentagens médias de miniestacas de $P$. angustifolia com calos, vivas e mortas, coletadas na primavera de 2007, outono e inverno de 2008.

\begin{tabular}{cccc}
\hline $\begin{array}{c}\text { Épocas } \\
\text { de coleta }\end{array}$ & $\begin{array}{c}\text { Miniestacas } \\
\text { com calos } \\
\mathbf{( \% )}\end{array}$ & $\begin{array}{c}\text { Miniestacas } \\
\text { vivas } \\
\mathbf{( \% )}\end{array}$ & $\begin{array}{c}\text { Miniestacas } \\
\text { mortas } \\
\mathbf{( \% )}\end{array}$ \\
\hline $\begin{array}{c}\text { Primavera } \\
\text { (outubro de 2007) }\end{array}$ & $8,8 \mathrm{~B}$ & $3,8 \mathrm{~B}$ & $42,5 \mathrm{AB}$ \\
$\begin{array}{c}\text { Outono } \\
\text { (abril de 2008) }\end{array}$ & $37,5 \mathrm{~A}$ & $25,0 \mathrm{~A}$ & $20,0 \mathrm{~B}$ \\
$\begin{array}{c}\text { Inverno } \\
\text { (junho de 2008) }\end{array}$ & $5,0 \mathrm{~B}$ & $0,0 \mathrm{C}$ & $50,0 \mathrm{~A}$ \\
\hline
\end{tabular}

Médias seguidas da mesma letra nas colunas não diferem estatisticamente pelo teste de Tukey ao nível de $5 \%$ de probabilidade.

Com relação à porcentagem de miniestacas mortas, o inverno e a primavera apresentaram médias estatisticamente semelhantes, sendo o inverno a época de coleta com valor médio numericamente superior. O manuseio durante a confecção das estacas também pode ter contribuído para a elevada taxa de mortalidade, apesar da imersão prévia em solução de ácido ascórbico.

Considerando a soma das porcentagens de estacas enraizadas e com calos, miniestacas instaladas no outono apresentaram valor mais elevado de estacas propensas ao enraizamento, seguido da primavera, confirmando os resultados obtidos por Ferriani (2006) para estacas semilenhosas da mesma espécie. Tais resultados sugerem que o armazenamento de reservas realizado pela espécie nas épocas de temperaturas mais baixas contribuíram para o processo de iniciação radicial.

\section{Conclusões}

A sobrevivência das minicepas de $P$. angustifolia apresenta variações de acordo com a época o ano. A produção de brotações (miniestacas) de $P$. angustifolia foi maior na primavera, seguida do outono e verão.

Miniestacas coletadas no inverno e na primavera apresentaram as maiores porcentagens de enraizamento adventício (45\%), porém o número e comprimento de raízes foram superiores no inverno.

\section{Referências}

AlCANTARA, G. B. Miniestaquia de Pinus taeda L. 2005. 77 f. Dissertação (Mestrado em Botânica) - Setor de Ciências Biológicas, Universidade Federal do Paraná, Curitiba.

ALFENAS, A. C.; ZAUZA, E. A. V.; MAFIA, R. G.; ASSIS, T. F. Clonagem e doenças do eucalipto. Viçosa, MG: UFV, 2004. 442 p.

ALMEIDA, F. D.; XAVIER, A.; DIAS, J. M. M.; PAIVA, H. N. Eficiência das auxinas (AIB e ANA) no enraizamento de miniestacas de clones de Eucalyptus cloeziana F. Muell. Revista Árvore, Viçosa, MG, v. 31, n. 3, p. 455-463, 2007.

BONGA, J. M. Vegetative propagation in relation to juvenility, maturity and rejuvenation. In BONGA, J. M.; DURZAN, D. J. Tissue culture in forestry. Netherlands: Canada Martinus Nijhoff, Dr. W. Junk, 1982. p. 387-412.

BRONDANI, G. E. Miniestaquia e micropropagação de Eucalyptus benthamii Maiden \& Cambage X Eucalyptus dunii Maiden. 2008. 130 f. Dissertação (Mestrado em Engenharia Florestal) - Universidade Federal do Paraná. Curitiba.

CARPANEZZI, A. A. Fundamentos para a reabilitação de ecossistemas florestais. In: GALVÃO, A. P. M.; PORFÍRIO-DASILVA, V. (Org.). Restauração florestal: fundamentos e estudos de caso. Colombo: Embrapa Florestas, 2005.

p. 27-45.

CUNHA, A. C. M. C. M.; WENDLING, I.; SOUZA JÚNIOR, L. Influência da presença ou ausência de folhas no enraizamento de miniestacas de corticeira-do-mato (Erythrina falcata Bentham) obtidas em sistema hidropônico. Colombo: Embrapa Florestas, 2003. 5 p. (Embrapa Florestas. Comunicado Técnico, 89).

CUNHA, A. C. M. C. M.; WENDLING, I.; SOUZA JÚNIOR, L. Produtividade e sobrevivência de minicepas de Eucalyptus benthamii Maiden et Cambage em sistema de hidroponia e em tubete. Ciência Florestal, Santa Maria, v. 15, n. 3, p. 307-310, 2005.

FERRARI, M.; GROSSI, F.; WENDLING, I. Influência da utilização de antioxidante na enxertia de erva-mate (Ilex paraguariensis Saint Hillaire). Colombo: Embrapa Florestas, 2004. 3 p. (Embrapa Florestas. Comunicado Técnico, 109).

FERRIANI, A. P.; BORTOLINI, M. F.; NOGUEIRA, A. C. Comportamento germinativo de sementes de vassourão-branco (Piptocarpha angustifolia Dusén) sob diferentes temperaturas e substratos. Informativo ABRATES, v. 15, n. 1-3, ago. 2005. Edição dos anais do Congresso Brasileiro de sementes, 2005, Foz do Iguaçu.

FERRIANI, A. P. Estaquia de vassourão-branco (Piptocarpha angustifolia Dusén) com uso do ácido indol-butírico. 2006. 100 f. Dissertação (Mestrado em Agronomia ) - Setor de Produção Vegetal, Universidade Federal do Paraná. Curitiba.

HARTMANN, H. T.; KESTER, D. E.; DAVIES JÚNIOR, F. T.; GENEVE, R. L. Plant propagation: principles and practices. 7th. ed. New York: Englewood Clipps, 2002, 880 p. 
HIGASHI, E. N.; SILVEIRA, R. L. V. A.; GONÇALVES, A. N. Propagação vegetativa de Eucalyptus: princípios básicos e sua evolução no Brasil. Circular Técnica IPEF, São Paulo, n. 192, 2000.

PAIVA, H. N.; GOMES, J. M. Propagação vegetativa de espécies florestais. Viçosa, MG: Universidade Federal de Viçosa, 1993. 40 p.

REIS, J. M. R.; CHALFUN, N. N. J.; LIMA, L. C. O.; LIMA, L. C. Efeito do estiolamento e do ácido indol butírico no enraizamento de estacas do porta-enxerto Pyrus calleryana Dcne. Ciência Agrotécnica, Lavras, MG, v. 24, n. 4, p. 931-938, 2000.

SANTOS, G. A. Propagação vegetativa de mogno, cedro rosa, jequitibá rosa e angico vermelho por miniestaquia. 2002. $75 \mathrm{f}$. Monografia (Graduação em Engenharia Florestal) - Universidade Federal de Viçosa. Viçosa, MG. 2002.

SEITZ, R. A. Algumas características ecológicas e silviculturais do vassourão-branco (Piptocarpha angustifolia Dusén). 1976. 114 f. Dissertação (Mestrado) - Universidade Federal do Paraná. Curitiba.

SOUZA, M. R.; ALMADO, R. P. Produção de mudas na CAF Santa Bárbara Ltda. Miniestaquia clonal em Eucalyptus sp. In: ROCHA, M. G. B. Melhoramento de espécies arbóreas nativas. Belo Horizonte: Instituto Estadual de Florestas, 2002. 171 p.

TITON, M.; XAVIER, A.; REIS, G. G; OTONI, W. C. Eficiência das minicepas e microcepas na produção de propágulos de clones de Eucalyptus grandis, Revista Árvore, Viçosa, MG, v. 27, n. 5, p. 619-625, 2003.

TORRES, A. G. M. Relação entre sazonalidade, desrama e carboidrato no crescimento do eucalipto na propagação vegetativa por miniestaquia. 2003. 65 f. Dissertação (Mestrado em Recursos Florestais) - Escola Superior de Agricultura "Luiz de Queiroz". Piracicaba, SP.

WENDLING, I.; XAVIER, A.; GOMES, J. M.; PIRES, I. E.; ANDRADE, H. B. Efeito do regulador de crescimento AIB na propagação de clones de Eucalyptus spp. por miniestaquia. Revista Árvore, Viçosa, MG, v. 24, n. 2, p. 187-192, 2000.
WENDLING, I. Rejuvenescimento de clones de Eucalyptus grandis por miniestaquia seriada e micropropagação. 2002. 105 f. Tese (Doutorado em Ciência Florestal) - Universidade Federal de Viçosa, Viçosa, MG.

WENDLING, I.; XAVIER, A. Miniestaquia seriada no rejuvenescimento de Eucalyptus. Pesquisa Agropecuária Brasileira, Brasília DF, v. 38, n. 4, p. 475-480, 2003.

WENDLING, I.; XAVIER, A.; PAIVA, H. N. Influência da miniestaquia seriada no vigor de minicepas de clones de Eucalyptus grandis. Revista Árvore, Viçosa, MG, v. 27, n. 5, p. 611-618, 2003.

WENDLING, I.; FERRARI, M. P.; DUTRA, L. F. Produção de mudas de corticeira-do-mato (Erythrina falcata Bentham) por miniestaquia a partir de propágulos juvenis. Colombo: Embrapa Florestas, 2005. (Embrapa Florestas. Comunicado técnico, 130).

WENDLING, I.; DUTRA, L. F.; GROSSI, F. Produção e sobrevivência de miniestacas e minicepas de erva-mate cultivadas em sistema semi-hidropônico. Pesquisa Agropecuária Brasileira, Brasília, DF, v. 42, n. 2, p. 289-292, 2007.

XAVIER, A.; SANTOS, G. A. Clonagem de espécies florestais nativas. In: ROCHA, M. G. B. Melhoramento de espécies arbóreas nativas. Belo Horizonte: Instituto Estadual de Florestas, 2002. $171 \mathrm{p}$.

XAVIER, A.; SANTOS, G. A.; OLIVEIRA, M. L. Enraizamento de miniestaca caulinar e foliar na propagação vegetativa de cedrorosa (Cedrela fissilis Vell.). Revista Árvore, Viçosa, MG, v. 27, n. 3, p. 351-356, 2003a.

XAVIER, A.; SANTOS, G. A.; WENDLING, I.; OLIVEIRA, M. L. Propagação vegetativa de cedro-rosa por miniestaquia. Revista Árvore, Viçosa, v. 27, n. 2, p. 139-143, 2003b.

ZOBEL, B.; TALBERT, J. Vegetative propagation. In: Applied forest tree improvement. North Carolina State University, 1984. $505 \mathrm{p}$. 